\title{
Symbiodinium spp. in colonies of eastern Pacific Pocillopora spp. are highly stable despite the prevalence of low-abundance background populations
}

\author{
Michael P. McGinley ${ }^{1, *}$, Matthew D. Aschaffenburg ${ }^{1}$, Daniel T. Pettay ${ }^{1}$, Robin T. Smith ${ }^{2}$, \\ Todd C. LaJeunesse ${ }^{3}$, Mark E. Warner ${ }^{1}$ \\ ${ }^{1}$ College of Earth, Ocean, and Environment, University of Delaware, Lewes, Delaware 19958, USA \\ ${ }^{2}$ Department of Biology, Florida International University, Miami, Florida 33199, USA \\ ${ }^{3}$ Department of Biology, The Pennsylvania State University, University Park, Pennsylvania 16802, USA
}

\begin{abstract}
A shift in the dominant Symbiodinium species within a coral colony may allow rapid acclimatization to environmental stress, provided that the new symbiont is better suited to prevailing conditions. In this study, the Symbiodinium diversity in Pocillopora corals was examined following a cold-water bleaching event in the Gulf of California. Individual colonies were differentially impacted by this event based upon their association with either the Symbiodinium ITS-2 type C1b-c (sensitive) or ITS-2 type D1 (tolerant). Real-time PCR indicated a high prevalence of an alternate and compatible Symbiodinium sp. (i.e. C1b-c or D1) residing at low-abundance background levels within many colonies both during and after a $1 \mathrm{yr}$ recovery interval (46 to $52 \%$ ). However, despite the potential for 'switching,' the dominant resident symbiont remained at high abundance during the recovery, with only 2 of 67 colonies $(3 \%)$ undergoing a change to the other Symbiodinium type. Pocillopora residing in the Gulf of California therefore maintain long-term associations dominated by a specific Symbiodinium sp., where potential competition by a second symbiont type is suppressed despite the temporary change in environmental conditions that would favor a shift in symbiosis toward a more stress-tolerant species.
\end{abstract}

KEY WORDS: Coral bleaching - Real-time PCR . Symbiodinium - Symbiosis - Pocillopora - Eastern Pacific

Resale or republication not permitted without written consent of the publisher

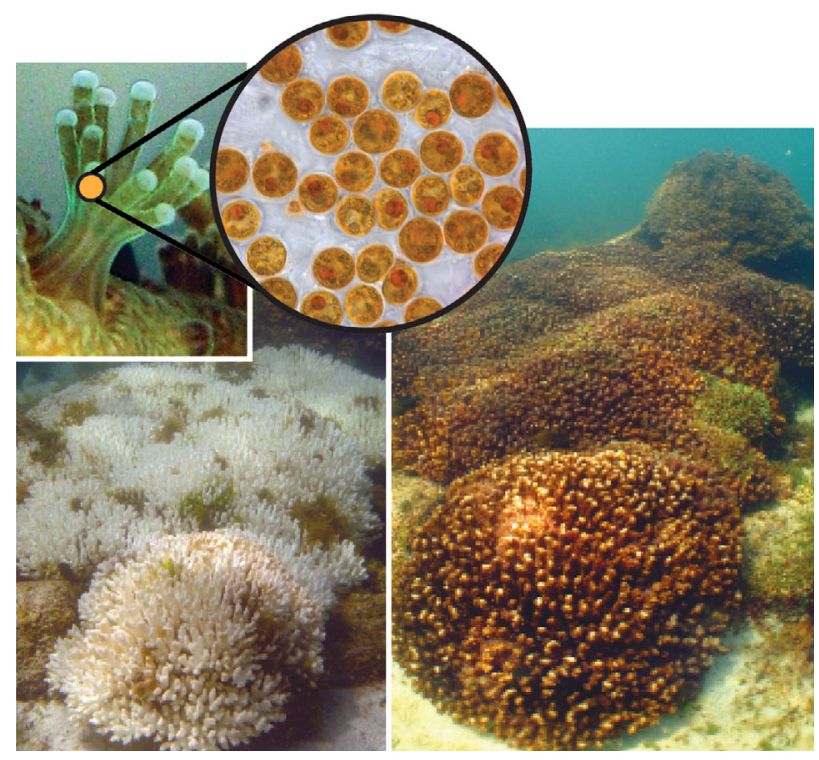

Resident Symbiodinium spp. remained stable within Pocillopora corals following a cold-water stress event off Baja California, Mexico, in 2008.

Photos: T. C. LaJeunesse, M.D. Aschaffenburg, D. T. Pettay

\section{INTRODUCTION}

The survival of a coral colony is dependent on the physiological limitations of both the cnidarian host and its endosymbiotic dinoflagellate (Symbiodinium spp.) under prevailing environmental conditions (Iglesias-Prieto \& Trench 1997). The physiological contribution of each partner determines the level of sensitivity or resiliency of a coral to environmental 
stress (Brown et al. 2002, Rowan 2004, Berkelmans \& van Oppen 2006, Baird et al. 2009, Wicks et al. 2012). When grown under identical conditions, genetically distinct isolates of Symbiodinium exhibit considerable differences in their ability to acclimatize to both light (Iglesias-Prieto \& Trench 1997, Reynolds et al. 2008, Hennige et al. 2009) and temperature stress (Berkelmans \& van Oppen 2006, Robison \& Warner 2006), both of which are important factors responsible for large-scale coral bleaching events (Fitt et al. 2001). Therefore, the physiological attributes of a coral's symbiont are important factors determining the persistence of coral communities subjected to acute and long-term changes in their resident environment (Sampayo et al. 2008, LaJeunesse et al. 2010a).

If corals continue to survive under the current rate of climate change (IPCC 2007), one mechanism for rapid physiological change could involve a shift in coral symbioses to Symbiodinium spp. better adapted to more stressful environmental conditions (e.g. higher temperatures; Baker 2001). Therefore, severe physiological stress and disruption of the normal symbiosis (i.e. bleaching) may present an opportunity for rapid acclimatization by allowing for the proliferation of a tolerant background symbiont population, a condition known as symbiont 'shuffling' (Rowan et al. 1997, Berkelmans \& van Oppen 2006, Jones et al. 2008, LaJeunesse et al. 2009). A coral species capable of associating with several symbiotic partners could possess an ecological advantage in its ability to adjust to different stressors imposed by global climate change.

Although most corals appear to develop highly specific and stable associations with particular algal partners (Goulet 2006), the recent use of increasingly sensitive molecular techniques (i.e. real-time PCR) have detected low-level, background symbiont populations that belong to a clade group different from the typical dominant symbiont (Loram et al. 2007, Mieog et al. 2007, Correa et al. 2009, Silverstein et al. 2012). These findings were used to infer that the potential of symbiont shuffling is higher than previously thought. However, in only a few cases has it been shown that background symbiont populations may be ecologically important during episodes of increasing stress (e.g. Berkelmans \& van Oppen 2006, LaJeunesse et al. 2009). Understanding the flexibility of different coral-algal symbioses, as well as the ecological role of background symbionts, is crucial to fully comprehending the biological impact that climate change will have on coral communities.

In 2008, an anomalous cold-water bleaching event differentially impacted colonies of Pocillopora resid- ing in the southern Gulf of California, in which corals harboring the sensitive symbiont, Symbiodinium ITS-2 type C1b-c, were severely bleached, while the colonies associated with Symbiodinium ITS-2 type D1 were largely unaffected (LaJeunesse et al. 2010a). The present study compared the temporal stability of these Symbiodinium communities within Pocillopora spp. at the end of the bleaching event (May 2008) and following a 1 yr recovery interval (June 2009) using real-time PCR. This sensitive detection technique confirmed that despite the potential for populations of D1 symbionts to proliferate and outcompete type C1b-c symbionts, the dominant symbiont remained remarkably stable during recovery for the majority of colonies.

\section{MATERIALS AND METHODS}

All experimental coral fragments were obtained from Punta Galeras Reef, Gulf of California (24'ㄴ $\left.1^{\prime} 15^{\prime \prime} \mathrm{N}, 110^{\circ} 17^{\prime} 05^{\prime \prime} \mathrm{W}\right)$, near La Paz, Mexico. In May 2008, fragments ( 4 to $5 \mathrm{~cm}$ in size) from 77 distinct parent colonies of Pocillopora spp. were sampled following a cold-water bleaching event, caused by an unusually strong La Niña cycle in this region (see LaJeunesse et al. 2010a), based on the visual characterization of bleached (completely white colony; $\mathrm{n}=43$ ) or non-bleached (brown colony; $\mathrm{n}=34$ ). This visual characterization of bleaching was confirmed by symbiont isolation and quantification, such that bleached colonies contained significantly fewer symbionts relative to coral fragments sampled 1 yr prior to the bleaching event at this same location in 2007, while there was no significant change in symbiont number for the same comparison in non-bleached fragments (LaJeunesse et al. 2010a). Initially, a fragment from each colony was analyzed for its original Symbiodinium composition (see below), mounted with marine epoxy to a labeled 1.5 inch PVC pipe coupler, and transplanted back to the reef site for a 1 yr recovery interval. In June 2009, all previously transplanted colony fragments were collected and again sampled for the genetic analysis of their Symbiodinium. Ten of the colonies (2 C1b-c and 8 D1 corals) were excluded from our analysis due to mortality or problems with extracting quality DNA ( $\mathrm{n}=$ 67 remaining colonies).

Small fragments were removed from each coral using bone cutters and preserved in a high salt $20 \%$ DMSO DNA preservation buffer prior to transport back to the USA (Seutin et al. 1991). A Wizard DNA extraction protocol (Promega) was applied using 
$1.0 \mathrm{~mm}$ glass beads to homogenize the tissue from each fragment. The genetic identity of the Symbiodinium sp. was initially examined using PCR-denaturing gradient gel electrophoresis (DGGE) of the ITS2 rDNA to characterize the dominant Symbiodinium sp. as either C1b-c or D1 (LaJeunesse et al. 2008). All samples were amplified using the 'ITS2 Clamp' and 'ITSintfor2' using a touchdown PCR protocol according to LaJeunesse (2002). The resulting PCR products were electrophoresed on an $8 \%$ polyacrylamide denaturing gradient gel (45 to $80 \%$ denaturant) for $16 \mathrm{~h}$ at $115 \mathrm{~V}$ (CBScientific System).

The samples were additionally analyzed using previously developed Clade B, C, and D specific realtime PCR primers designed to target differences in the rDNA (Correa et al. 2009). This assay provides a greater level of sensitivity than PCR-DGGE for detecting the presence/absence of any low-level, background populations of Symbiodinium (Mieog et al. 2007). The DNA concentration for each sample was diluted to $10 \mathrm{ng} \mathrm{ul}^{-1}$ with autoclaved $\mathrm{H}_{2} \mathrm{O}$. Reactions were performed on an ABI Prism 7500 Sequence Detection System (Applied Biosystems) using 2 technical replicates for each sample. Each plate contained a no-template control and a known reference sample (cultured Symbiodinium DNA from Clade B, C, or D), to account for differences between subsequent runs. Each PCR reaction consisted of $2 \mu \mathrm{l}$ $\mathrm{H}_{2} \mathrm{O}, 5 \mu \mathrm{l}$ SensiMix SYBR mastermix (Bioline), $1 \mu \mathrm{l}$ each of forward and reverse primers $(10 \mu \mathrm{M}$ Clade $\mathrm{C}$ and $1 \mu \mathrm{M}$ Clade D), and $1 \mu \mathrm{l}$ DNA $\left(10 \mathrm{ng} \mathrm{\mu l}^{-1}\right)$ in $10 \mu \mathrm{l}$ total volume reactions. The subsequent thermal cycler conditions followed Correa et al. (2009). Cycle threshold $\left(\mathrm{C}_{\mathrm{T}}\right)$ values were established using a common fluorescence threshold value of 0.01 and an automatic baseline.

The upper limit of a 'positive' amplification was conservatively set at $31.6,30.3$, and $32.3 \mathrm{C}_{\mathrm{T}}$ for Clade B, C, and D Symbiodinium, respectively. These cutoff values were chosen as our limit of detection following the analysis of a series of seven 10-fold serial dilutions (10.0 to $0.00001 \mathrm{ng} \mathrm{ll}^{-1}$ ) of B1 (Culture \#13), C1b-c, or D1 DNA in the presence of a constant DNA concentration $\left(10 \mathrm{ng} \mathrm{Hl}^{-1}\right.$ ) of the opposing symbiont.
The DNA samples used to construct each dilution were extracted from pelleted Symbiodinium cells (isolated from the host or a culture [B1] via centrifugation) and screened by real-time PCR to ensure the absence of any background symbionts. The conservative cutoff point represents the highest $\mathrm{C}_{\mathrm{T}}$ values at which the dilution series remained linear $\left(\mathrm{C}_{\mathrm{T}}\right.$ versus log scale concentration), with a standard deviation of $<0.25$ among the technical replicates.

The resulting $\mathrm{C}_{\mathrm{T}}$ values for the $\mathrm{C}$ and $\mathrm{D}$ primer sets were used to designate each sample into one of the following categories: C1b-c or D1 only (a single clade detected), C1b-c/D1 mixture $\left(<3 \mathrm{C}_{\mathrm{T}}\right.$ difference between clades), C1b-c dominated with a D1 in background (C1b-C $\gg D 1$; Clade $\mathrm{D}>3 \mathrm{C}_{\mathrm{T}}$ values higher than Clade $\mathrm{C}$ ), and D1 dominated with a C1b$\mathrm{C}$ in background (D1 $\gg \mathrm{C} 1 \mathrm{~b}-\mathrm{C}_{\text {; }}$ Clade $\mathrm{C}>3 \mathrm{C}_{\mathrm{T}}$ values higher than Clade D). The frequencies of each $S y m-$ biodinium type characterized using real-time PCR during May 2008 and June 2009 were analyzed by an exact Pearson's chi-squared test for independence (StatXact 4; Cytel Software) against the null hypothesis that the symbiont distribution was homogeneous between the 2 sampling points.

\section{RESULTS AND DISCUSSION}

As previously reported (LaJeunesse et al. 2010a), DGGE analysis of the ITS2 PCR amplifications revealed that the majority of the bleached Pocillopora colonies were dominated by Symbiodinium C1b-c ( $\mathrm{n}=36$ ), with only a few colonies harboring either a C1b-c/D1 mixture $(\mathrm{n}=3)$ or solely D1 $(\mathrm{n}=2$; Table 1). Conversely, most of the non-bleached colonies associated with Symbiodinium D1 (n = 24), while $\mathrm{C} 1 \mathrm{~b}-\mathrm{c}$ was the dominant symbiont in only 2 of these colonies (for an extensive survey, see LaJeunesse et al. 2010a). Our subsequent application of real-time PCR identified a considerably higher proportion of low-abundance, background populations of Clade $\mathrm{C}$ or $\mathrm{D}$ residing within these corals than was detected by ITS2-DGGE (Fig. 1). Interestingly, Clade B Symbiodinium was not detected in any

Table 1. Symbiodinium spp. associated with Pocillopora. ITS2-DGGE identification during (May 2008) and after (June 2009) recovery from the bleaching event

\begin{tabular}{|lcccccccccc|}
\hline & \multicolumn{3}{c}{ Bleached } & \multicolumn{4}{c}{ Non-bleached } & \multicolumn{3}{c|}{ Total } \\
& C1b-c & D1 & C/D mix & C1b-c & D1 & C/D mix & C1b-c & D1 & C/D mix \\
\hline May 2008 & 36 & 2 & 3 & 2 & 24 & - & 38 & 26 & 3 \\
June 2009 & 38 & - & 3 & 2 & 24 & - & 40 & 24 & 3 \\
\hline
\end{tabular}




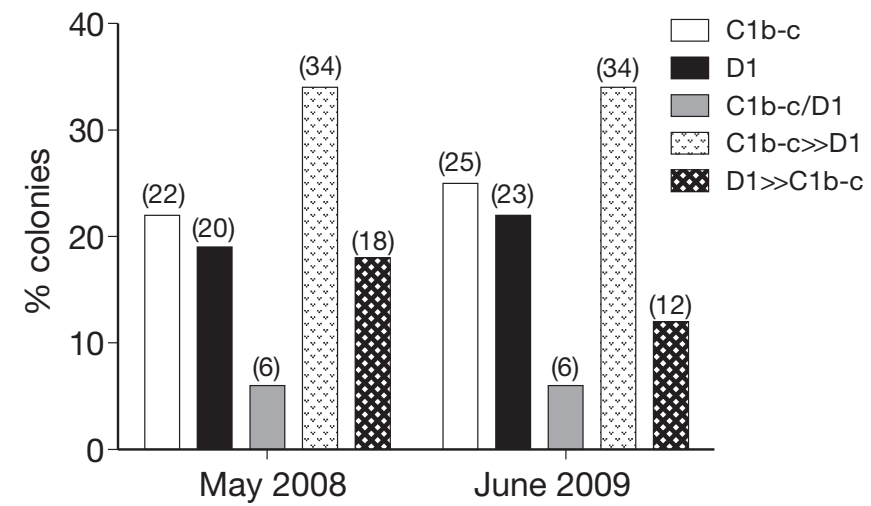

Fig. 1. Symbiodinium community structure in Pocillopora colonies. Real-time PCR characterization $(\mathrm{n}=67)$ immediately after a cold-water bleaching event (May 2008) and following a 1 yr recovery interval (June 2009). All corals were classified into 1 of 5 categories: C1b-c only, D1 only, C1bc/D1 mixture, dominant C1b-c with background D1 (C1b-c $\gg$ D1), and dominant D1 with background C1b-c (D1 $\gg$ C1b-c). Numbers above each bar represent the percentage of corals corresponding to a particular category

of the corals from either time point, although Symbiodinium B1 was identified in a small number of bleached colonies sampled in May 2008 in areas outside of our recovery plot (LaJeunesse et al. 2010a). In May 2008, 2 mo following the cold-water bleaching event when affected colonies were bleached but recovering, $52 \%$ of all Pocillopora colonies contained a single dominant Symbiodinium type (C1b-c or D1) along with a detectable background population of the alternate symbiont $(34 \% \mathrm{C} 1 \mathrm{~b}-\mathrm{c} \gg \mathrm{D} 1,18 \% \mathrm{D} 1 \gg$ C1b-c; Fig. 1). Following the 1 yr recovery (June 2009), the Symbiodinium community structure was remarkably stable despite the high percentage of background symbionts (Fig. 1; exact Pearson's chisquared test, $\mathrm{p}=0.891$ ).

Recent applications of real-time PCR have detected the prevalence of low-abundance Symbiodinium types associated with corals that were previously thought to harbor only a single or small subset of different symbionts (Loram et al. 2007, Mieog et al. 2007, Correa et al. 2009, Silverstein et al. 2012). These studies suggested that the prevalence of mixed symbiont populations and/or potential for symbiont shuffling within many corals is greater than previously reported (Goulet 2006). However, the ecological significance and overall contribution of such background symbionts to the holobiont fitness remains enigmatic, as many of the corals examined are rarely (if ever) dominated by one of the additional Symbiodinium types detected (Thornhill et al. 2006b, Goulet 2007, Stat et al. 2009, LaJeunesse et al. 2010b).

If symbiont shuffling was frequent among eastern Pacific Pocillopora colonies, one may expect a greater proliferation of Symbiodinium D1 given the increased tolerance during bleaching conditions (both warm and cold water) imparted by harboring this particular symbiont (Glynn et al. 2001, LaJeunesse et al. 2010a). However, a comparison of fragments within the individual colonies during and after the recovery period revealed that a large majority of colonies remained dominated by the same Symbiodinium type $(67 \%)$ or showed minor differences in the appearance or disappearance of the background species $(30 \%$; Fig. 2). Overall, only $3 \%$ of Pocillopora colonies $(n=2)$ experienced a switch in their dominant symbiont population (i.e. a shift from D1 to $\mathrm{C} 1 \mathrm{~b}-\mathrm{c}[\mathrm{n}=1]$ or a shift from D1 to a C1b-c/D1 mixture $[n=1]$ ), suggesting that the occurrence of a shuffling event is exceptionally rare.

The dynamics of the background symbiont populations may suggest limited influence of preferential growth or demise of a particular Symbiodinium sp. in response to the bleaching event (Fig. 2b,c). For example, the appearance of a background D1 population was detected in 6 coral colonies after the recovery (i.e. absent in May 2008 and found in June 2009), while this same symbiont was no longer detected as a background population in 7 other colonies following the same interval (Fig. 2b,c). The haphazard pattern of background symbiont dynamics is possibly a sampling artifact due to the removal of coral tissue from different locations between the respective years. The relative abundance of each Symbiodinium sp., as well as distinct genotypes within a single symbiont species, can vary at different locations within some individual colonies (Pettay et al. 2011).

The monitoring of background symbionts over time allows us to examine in detail the dynamics of Symbiodinium diversity in colonies following environmental stress. The present study confirms the presence of additional low-abundance Symbiodinium spp. using a technique with greater detection resolution (real-time PCR; Loram et al. 2007, Mieog et al. 2007, Correa et al. 2009, Silverstein et al. 2012) and examines their dynamics during bleaching recovery (LaJeunesse et al. 2009). In contrast to certain expectations (Baker 2001, Silverstein et al. 2012), remarkable stability in resident Symbiodinium populations suggest that processes are at work that suppress the proliferation of a compatible symbiont present in background over the prevailing dominant symbiont population. The fidelity in partner combination during and after a bleaching event, in the presence of background populations of a second compatible symbiont, supports the idea that currently unknown molecular or cellular processes govern the dynamics 
(a) Community Dynamics

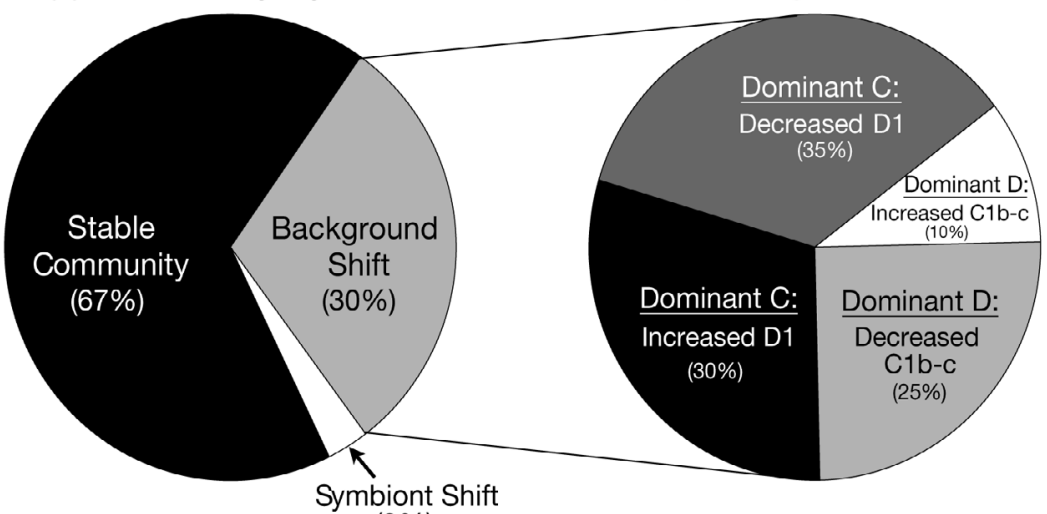

$(3 \%)$

(c) Individual Colonies
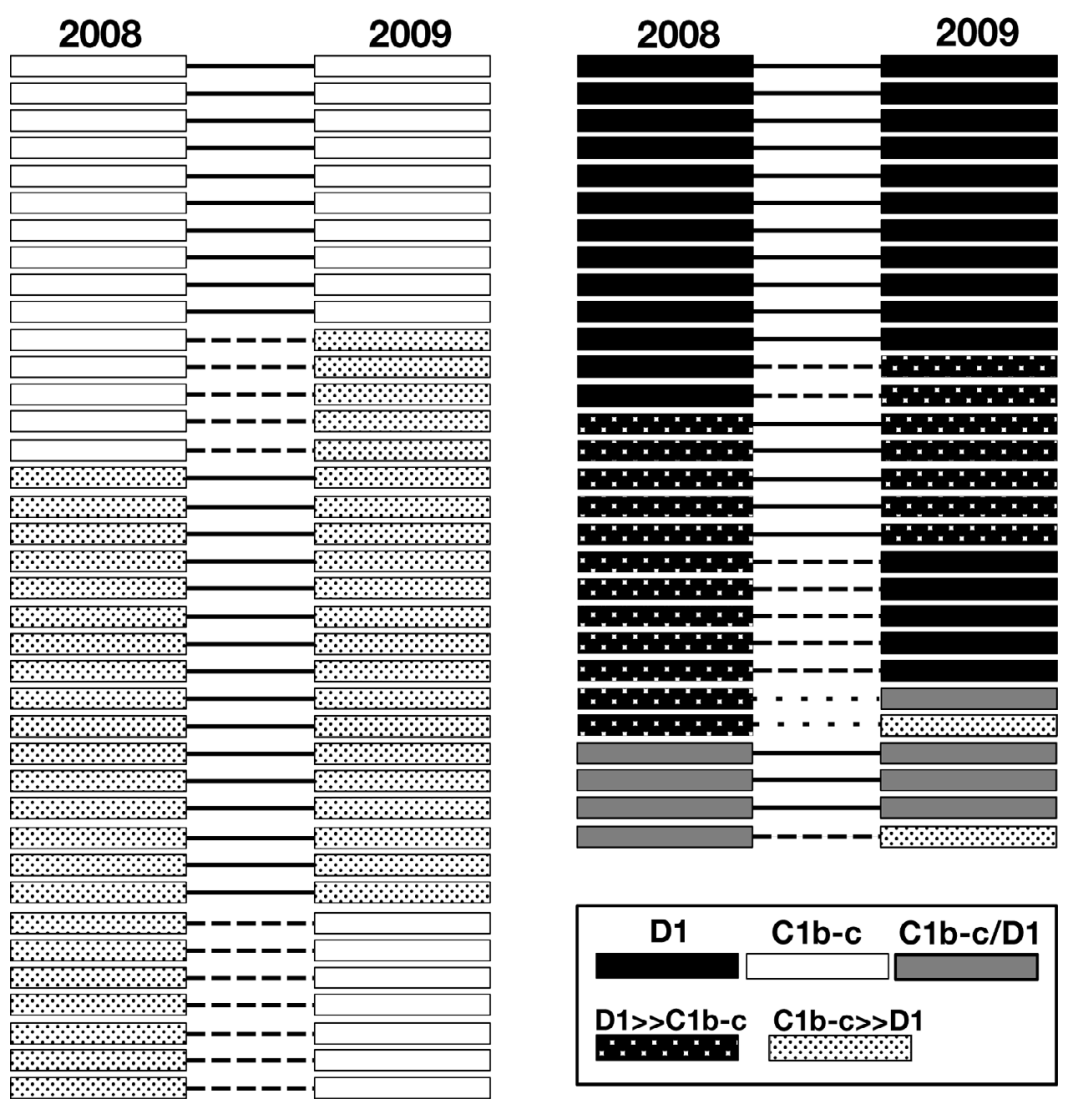

Fig. 2. Symbiodinium community dynamics within the Pocillopora colonies over the recovery interval. (a) Comparison of the Symbiodinium community within a coral colony, labeled as stable, background shift (stable dominant symbiont with the disappearance/appearance of a background population), or symbiont shift (change in the dominant symbiont). (b) Corals experiencing a background shift, further categorized based on their dominant symbiont type as well as the appearance ('Increased') or disappearance ('Decreased') of a background population after the 1 yr recovery interval. (c) Real-time PCR characterization of the Symbiodinium within individual Pocillopora colonies immediately after the bleaching event (2008) and following a 1 yr recovery (2009). Symbiont dynamics between sampling points: - = stable community; - - - = background shift; $\cdots . . \cdot$ = symbiont shift between these host-symbiont associations (Weis et al. 2001, Rodriguez-Lanetty et al. 2006, Wood-Charlson et al. 2006, Dunn \& Weis 2009) and suggests that the selection process may be imprinted on these corals during early development (Nyholm \& McFall-Ngai 2004). However, environmentally mediated forces and/or physiological characteristics of each symbiont type could be equally or more important in preventing the proliferation of a background symbiont (i.e. environmental patterns did not favor a symbiont change). For example, a rapid recovery in the remaining $\mathrm{C} 1 \mathrm{~b}-\mathrm{C}$ symbionts may have been facilitated by more efficient nutrient acquisition and faster growth in this alga in the initial recovery interval. More research is required to evaluate factors influencing the stability of these symbioses and how specific stressors (e.g. exposure to anomalously warm vs. cold-water temperature) may differentially influence these associations.

The stable symbiosis of these Pocillopora colonies differs significantly from similar investigations with different types of Symbiodinium C and D, such as Acropora millepora, which exhibited a higher proportion of Clade D dominated corals following a bleaching event (Berkelmans \& van Oppen 2006, Jones et al. 2008). This different outcome is not surprising given that the fidelity of a coral-algal symbiosis can vary depending on both the geographic location and the combination of each symbiotic partner (Thornhill et al. 2006a, LaJeunesse et al. 2009). Furthermore, different strategies of symbiont acquisition could also be important between these 2 coral species. Pocillopora in the Gulf of California are broadcast spawners but vertically transmit their symbionts to their progeny during egg development (Glynn et al. 1991), whereas A. millepora horizontally acquires its symbiont from the surrounding environment (van Oppen 2004). The symbioses of corals with vertical modes of symbiont transmission usually remain stable during and after exposure to physiological stressors (Thornhill et al. 2006b, Sampayo et al. 2008, Stat et al. 2009). The 
coupling of host and symbiont life histories in eastern Pacific Pocillopora colonies may favor greater integration and stability that is less responsive to external environmental conditions and limits or prevents competition from other symbionts.

Silverstein et al. (2012) proposed that a gradient of specificity exists based on the frequency at which a coral contains background populations of an additional Symbiodinium clade. What is the ecological significance of background Symbiodinium sp. detected among various colonies? This answer can only be gained through the long-term examination of colonies in natural and experimental settings exposed to environmental change. Indeed, the existence of multiple symbionts within the colonies of certain host species may undergo rapid change when exposed to different environmental conditions (e.g. Montastraea complex; Rowan et al. 1997, Baker 2001, Toller et al. 2001, Chen et al. 2005). For other coral species, environmental stress may lead to the temporary dominance (for months to years) of an uncommon opportunistic symbiont (Thornhill et al. 2006a, Jones et al. 2008, LaJeunesse et al. 2009). Our data indicate that some coral-dinoflagellate associations are stable over time despite the presence of background populations of a different yet homologous (i.e. compatible) symbiont species. Therefore, although real-time PCR can routinely detect a high frequency of low-abundance Symbiodinium representing different clades in various host species, the stability and relative abundance of these populations must be examined over time to assess the ecological significance of the background symbionts.

Acknowledgements. We thank the faculty and staff at the Universidad Autonoma de Baja California Sur Marine Station at Pichilingue, in particular H. Reyes-Bonilla and S. Flores Ramirez. This research was funded by the National Science Foundation (IOB 544765 to M.E.W. and IOB 544854 to T.C.L.), University of Delaware and Pennsylvania State University.

\section{LITERATURE CITED}

Baird AH, Bhagooli R, Ralph PJ, Takahashi S (2009) Coral bleaching: the role of the host. Trends Ecol Evol 24:16-20

Baker AC (2001) Reef corals bleach to survive change. Nature 411:765-766

Berkelmans R, van Oppen MJH (2006) The role of zooxanthellae in the thermal tolerance of corals: a 'nugget of hope' for coral reefs in an era of climate change. Proc Biol Sci 273:2305-2312

Brown BE, Downs CA, Dunne RP, Gibb SW (2002) Exploring the basis of thermotolerance in the reef coral Goniastrea aspera. Mar Ecol Prog Ser 242:119-129

Chen CA, Wang JT, Fang LS, Yang YW (2005) Fluctuating algal symbiont communities in Acropora palifera (Scleractinia: Acroporidae) from Taiwan. Mar Ecol Prog Ser 295:113-121

Correa AMS, McDonald MD, Baker AC (2009) Development of clade-specific Symbiodinium primers for quantitative PCR (qPCR) and their application to detecting clade D symbionts in Caribbean corals. Mar Biol 156:2403-2411

Dunn SR, Weis VM (2009) Apoptosis as a post phagocytic winnowing mechanism in a coral-dinoflagellate mutualism. Environ Microbiol 11:268-276

Fitt W, Brown B, Warner M, Dunne R (2001) Coral bleaching: interpretation of thermal tolerance limits and thermal thresholds in tropical corals. Coral Reefs 20:51-65

Glynn PW, Gassman NJ, Eakin CM, Cortes J, Smith DB, Guzman HM (1991) Reef coral reproduction in the eastern Pacific: Costa Rica, Panama and Galápagos Islands (Ecuador). Part I. Pocilloporidae. Mar Biol 109:355-368

Glynn PW, Mate JL, Baker AC, Calderon MO (2001) Coral bleaching and mortality in Panama and Ecuador during the 1997-1998 El Niño Southern Oscillation Event: spatial/temporal patterns and comparisons with the 1982-1983 event. Bull Mar Sci 69:79-109

Goulet TL (2006) Most corals may not change their symbionts. Mar Ecol Prog Ser 321:1-7

Goulet TL (2007) Most scleractinian corals and octocorals host a single symbiotic zooxanthella clade. Mar Ecol Prog Ser 335:243-248

Hennige SJ, Suggett DJ, Warner ME, McDougall KE, Smith DJ (2009) Photobiology of Symbiodinium revisited: bio-physical and bio-optical signatures. Coral Reefs 28: 179-195

Iglesias-Prieto R, Trench RK (1997) Acclimation and adaptation to irradiance in symbiotic dinoflagellates. II. Response of chlorophyll-protein complexes to different photon-flux densities. Mar Biol 130:23-33

IPCC (2007) Synthesis report. Contribution of Working Groups I, II and III to the Fourth Assessment Report of the Intergovernmental Panel on Climate Change. Intergovernmental Panel on Climate Change, Geneva, Switzerland

Jones AM, Berkelmans R, van Oppen MJH, Mieog JC, Sinclair W (2008) A community change in the algal endosymbionts of a scleractinian coral following a natural bleaching event: field evidence of acclimatization. Proc Biol Sci 275:1359-1365

LaJeunesse TC (2002) Diversity and community structure of symbiotic dinoflagellates from Caribbean coral reefs. Mar Biol 141:387-400

LaJeunesse TC, Smith R, Walther M, Pinzón J and others (2010a) Host-symbiont recombination versus natural selection in the response of coral-dinoflagellate symbioses to environmental disturbance. Proc Biol Sci 277: 2925-2934

LaJeunesse TC, Pettay DT, Sampayo EM, Phongsuwan N and others (2010b) Long-standing environmental conditions, geographic isolation and host-symbiont specificity influence the relative ecological dominance and genetic diversification of coral endosymbionts in the genus Symbiodinium. J Biogeogr 37:785-800

LaJeunesse TC, Bonilla HR, Warner ME, Wills M, Schmidt GW, Fitt WK (2008) Specificity and stability in high latitude eastern Pacific coral-algal symbioses. Limnol Oceanogr 53:719-727

LaJeunesse TC, Smith RT, Finney J, Oxenford H (2009) Outbreak and persistence of opportunistic symbiotic dinofla- 
gellates during the 2005 Caribbean mass coral 'bleaching'event. Proc Biol Sci 276:4139-4148

Loram JE, Boonham N, O'Toole P, Trapido-Rosenthal HG, Douglas AE (2007) Molecular quantification of symbiotic dinoflagellate algae of the genus Symbiodinium. Biol Bull 212:259-268

Mieog JC, Oppen MJH, Cantin NE, Stam WT, Olsen JL (2007) Real-time PCR reveals a high incidence of Symbiodinium clade $\mathrm{D}$ at low levels in four scleractinian corals across the Great Barrier Reef: implications for symbiont shuffling. Coral Reefs 26:449-457

Nyholm SV, McFall-Ngai M (2004) The winnowing: establishing the squid-Vibrio symbiosis. Nat Rev Microbiol 2: 632-642

Oppen MJH (2004) Mode of zooxanthella transmission does not affect zooxanthella diversity in acroporid corals. Mar Biol 144:1-7

Pettay DT, Wham DC, Pinzón JH, LaJeunesse TC (2011) Genotypic diversity and spatial-temporal distribution of Symbiodinium clones in an abundant reef coral. Mol Ecol 20:5197-5212

Reynolds JMC, Bruns BU, Fitt WK, Schmidt GW (2008) Enhanced photoprotection pathways in symbiotic dinoflagellates of shallow-water corals and other cnidarians. Proc Natl Acad Sci USA 105:13674-13678

Robison JD, Warner ME (2006) Differential impacts of photoacclimation and thermal stress on the photobiology of four different phylotypes of Symbiodinium (Pyrrhophyta). J Phycol 42:568-579

Rodriguez-Lanetty M, Wood-Charlson EM, Hollingsworth LL, Krupp DA, Weis VM (2006) Temporal and spatial infection dynamics indicate recognition events in the early hours of a dinoflagellate/coral symbiosis. Mar Biol 149:713-719

Rowan R (2004) Coral bleaching: thermal adaptation in reef coral symbionts. Nature 430:742

Rowan R, Knowlton N, Baker A, Jara J (1997) Landscape ecology of algal symbionts creates variation in episodes of coral bleaching. Nature 388:265-269

Editorial responsibility: Charles Birkeland, Honolulu, Hawaii, USA
Sampayo EM, Ridgway T, Bongaerts P, Hoegh-Guldberg O (2008) Bleaching susceptibility and mortality of corals are determined by fine-scale differences in symbiont type. Proc Natl Acad Sci USA 105:10444-10449

Seutin G, White BN, Boag PT (1991) Preservation of avian blood and tissue samples for DNA analyses. Can J Zool 69:82-90

Silverstein RN, Correa AMS, Baker AC (2012) Specificity is rarely absolute in coral-algal symbiosis: implications for coral response to climate change. Proc R Soc Lond B 279:2609-2618

Stat M, Loh WKW, LaJeunesse TC, Hoegh-Guldberg O, Carter DA (2009) Stability of coral-endosymbiont associations during and after a thermal stress event in the southern Great Barrier Reef. Coral Reefs 28:709-713

Thornhill DJ, LaJeunesse TC, Kemp DW, Fitt WK, Schmidt GW (2006a) Multi-year, seasonal genotypic surveys of coral-algal symbioses reveal prevalent stability or postbleaching reversion. Mar Biol 148:711-722

Thornhill DJ, Fitt WK, Schmidt GW (2006b) Highly stable symbioses among western Atlantic brooding corals. Coral Reefs 25:515-519

Toller WW, Rowan R, Knowlton N (2001) Zooxanthellae of the Montastraea annularis species complex: patterns of distribution of four taxa of Symbiodinium on different reefs and across depths. Biol Bull 201:348-359

Weis VM, Reynolds WS, deBoer MD, Krupp DA (2001) Hostsymbiont specificity during onset of symbiosis between the dinoflagellates Symbiodinium spp. and planula larvae of the scleractinian coral Fungia scutaria. Coral Reefs 20:301-308

Wicks LC, Gardner JPA, Davy SK (2012) Host tolerance, not symbiont tolerance, determines the distribution of coral species in relation to their environment at a Central Pacific atoll. Coral Reefs 31:389-398

Wood-Charlson EM, Hollingsworth LL, Krupp DA, Weis VM (2006) Lectin/glycan interactions play a role in recognition in a coral/dinoflagellate symbiosis. Cell Microbiol 8:1985-1993

Submitted: May 3, 2012; Accepted: July 2, 2012

Proofs received from author(s): July 26, 2012 